\title{
Investigation on Quick Fabrication of n-type Filled Skutterudites
}

\author{
YAO Zheng ${ }^{1,2}$, QIU Peng-Fei ${ }^{2}$, LI Xiao-Ya ${ }^{2}$, CHEN Li-Dong ${ }^{2}$ \\ (1. University of Chinese Academy of Sciences, Beijing 100049, China; 2. Shanghai Institute of Ceramics, Chinese Academy of \\ Sciences, Shanghai 200050, China)
}

\begin{abstract}
The cost-effective fabrication of $\mathrm{CoSb}_{3}$-based filled skutterudites (SKD) thermoelectric materials is a bottleneck issue preventing their successful commercial application. In this study, we employed a simple and scalable process to simultaneously produce a rapid formation and consolidation of n-type filled skutterudites. This method, consisting of RF-induction melting, quenching and spark plasma sintering (SPS), required less than a half-hour, significantly shorter than conventional process of furnace melting (over $24 \mathrm{~h}$ ), annealing (about one week) and SPS. The fabricated bulk SKD materials possessed homogeneous composition and structures with a good thermoelectric performance which are analogous to those materials fabricated according to a conventional process. The homogeneous microstructures and phase composition distribution which was a result of the simultaneously proceeded rapid reaction and densification of the grinding-destructed dendrite networks of the $\mathrm{Sb} / \mathrm{CoSb} / \mathrm{CoSb}_{2}$ peritectic structure formed in the RF-induction melting and quenching. The good thermoelectric TE performance and the very low consumption of process time and energy would make this simple process a potential and practical method for industrial-level mass production of filled skutterudite thermoelectric materials.
\end{abstract}

Key words: filled skutterudites; melting-quenching/SPS; microstructure; thermoelectric performance

Thermoelectric (TE) technology offers the possibility to directly convert waste heat into usable electricity. The energy conversion efficiency of TE materials mainly depends on the so-called dimensionless figure of merit $Z T=\alpha^{2} \sigma T / \kappa$, where $\alpha$ is the Seebeck coefficient, $\sigma$ is the electrical conductivity, $T$ is the operation temperature and $\kappa$ is the thermal conductivity ${ }^{[1-2]}$. In the past decade, numerous high-performance TE materials have been reported $^{[3-9]}$. Amongst them, $\mathrm{CoSb}_{3}$-based filled skutterudites are the most promising candidate for TE power generator applications due to their high $Z T S$ and good mechanical strength $^{[10]}$. Currently, research on filled skutterudites has mainly focused on device technology and mass fabrication, while the further enhancement of ZTs is also a long-term target ${ }^{[11-12]}$.

The fabrication process for filled skutterudites generally includes the synthesis of single phase SKD powder and its subsequent densification. The SPS technique has been widely employed for fabricating dense bulk TE materials with advantages of short sintering time and suppressed grain growth ${ }^{[13]}$. As compared to the densification process, the powder preparation is more time-consuming, and therefore has become a bottleneck in terms of industrial-level massive fabrication of filled skutterudites. Melting-quenching/annealing process is a commonly used and conventional method for the fabrication of skutterudite powder ${ }^{[14-16]}$. In this process, melt-grown ingots experience a long-term annealing period (about one week) at elevated temperature to form a pure filled skutterudite phase. This method is time and energy-consuming. Urgent demands for fast and simple fabrication method with low energy-consuming but good microstructure-controllability have arisen from the commercialization of thermoelectric power generation technology. Recently, many efforts have been carried out to deal with this issue. Some new methods, such as mechanical alloying ${ }^{[17-18]}$, microwave heating ${ }^{[19]}$, and self-propagating high temperature synthesis $^{[20-21]}$, have been adopted to prepare filled skutterudite powder. Nevertheless, it has been reported that a pure filled skutterudite phase with high filling fraction is very difficult to be achieved by these methods due to the complex cage-like crystal structure of filled skutterudite and the $\mathrm{Co}-\mathrm{Sb}$ peritectic segregation during the reaction. 
Besides the efforts to simplify the preparation process for filled skutterudite powder, other approaches looking into formation and densification of filled skutterudites simultaneously during the SPS process have also been reported recently. The most typical example is the meltspinning/SPS method ${ }^{[22-23]}$. The product after melt-spun, containing a complex mixture of amorphous phase and nano-grain SKD, can be converted to pure filled skutterudite crystalline bulk with high density by SPS. As compared with the conventional melting-quenching/ annealing/SPS method, this melt-spinning/SPS method is efficient and less-time consuming, though the further optimization of both the melt-spinning equipment and process parameters is still challenging in order to develop an industrial-level production technology. Recently, Yu, et al ${ }^{[24]}$ reported another quick method (melting-quenching/ SPS) to prepare p-type barium and indium filled skutterudites. They melted the raw materials at elevated temperature using an elemental-heating furnace and then quenched them in oil. They obtained ingots containing a mixture of $\mathrm{Sb}, \mathrm{CoSb}, \mathrm{CoSb}_{2}$ and $\mathrm{BaSb}$ (or InSb). Then, they ground the quenched ingot into fine powders and sintered them directly by SPS. Interestingly, they found that a pure filled skutterudite phase was directly obtained after SPS without pre-annealing. This method is in principle similar to the melting-spin/SPS technique, but it is simpler and cheaper. For this simple fabrication process, further investigations such as on the solid reaction mechanism during SPS for both the p-type and n-type SKD are essential for establishing an industrially applicable technique.

In this study, we have adopted the melting-quenching/SPS process proposed by $\mathrm{Yu}$, et al. to prepare n-type $\mathrm{Yb}_{0.3} \mathrm{Co}_{4} \mathrm{Sb}_{12}$ filled skutterudite bulk material. The induction melting was adopted instead of the furnace heating process, because the induction melting has the advantages of rapidly heating and self-stirring effect, which can greatly shorten the evenly time of the liquid as compared with the traditional furnace heating. The quenched ingots were ground into fine powder and then sintered directly by SPS at several specified temperatures for different durations. This method required less than $30 \mathrm{~min}$ of total high temperature processing, including $5 \mathrm{~min}$ or less for induction melting and $20 \mathrm{~min}$ or less for SPS. The microstructure, chemical composition, $\mathrm{Yb}$ filling fraction, and TE performance of the obtained samples were systematically characterized. The $\mathrm{Yb}_{0.3} \mathrm{Co}_{4} \mathrm{Sb}_{12}$ phases with $Z T S$ comparable with those by the traditional method were successfully achieved using this simple and quick method. The correspondingly reaction mechanisms during the SPS process were also discussed.

\section{Experimental}

The raw materials, $\mathrm{Yb}(99.98 \%$, ingot), Co $(99.95 \%$, shot), and $\mathrm{Sb}$ (99.99\%, shot), were weighed in stoichiometric ratios and loaded into quartz tube with carbon crucible (inner diameter $\phi 15 \mathrm{~mm}$ ). The tube was sealed under a pressure of $10^{-3} \mathrm{~Pa}$ and then melted by a home-made RF-induction heating instrument. After holding at $1353 \mathrm{~K}$ for $300 \mathrm{~s}$, the sealed ampoule was quenched in supersaturated salt water. Then, the quenched ingot, about $20 \mathrm{~g}$, was crushed and ground into fine powder, and screened through a 200 mesh sieve. The obtained powder was then directly sintered by SPS under a pressure of $60 \mathrm{MPa}$ at different conditions. The sintering temperatures were chosen as $863 \mathrm{~K}, 898 \mathrm{~K}$, and $943 \mathrm{~K}$, respectively. The dwelling time at specified temperatures was chosen as $5 \mathrm{~min}$ and $15 \mathrm{~min}$. The sintered products were named as $863 \mathrm{~K}-5$ min, $898 \mathrm{~K}-5 \mathrm{~min}, 943 \mathrm{~K}-5 \mathrm{~min}$ and $943 \mathrm{~K}-15 \mathrm{~min}$, respectively, based on their own sintering temperature and keeping period. A sample with the same composition as those by the above mentioned method was also prepared by using the traditional melting-quenching/annealing/SPS method (Ref. [25]), and named as TM for comparison.

The samples prepared by the melting-quenching/SPS method were examined by powder X-ray diffraction (XRD, Rigaku Rint2000, $\mathrm{Cu} \mathrm{K} \alpha$ ), scanning electron microscopy (SEM, ZEISS SUPRA 55) and electron energy dispersive spectroscopy (EDS, OXFORD Aztec X-Max80). The Yb filling fractions in the filled skutterudite matrix were collected by EDS at 12 randomly chosen grains. The relative contents of the secondary phases were estimated simultaneously according to the different contrast in SEM results via the Image Tools 3.0 software analysis. The densities of the sintered samples were measured using the Archimedes method. The Seebeck coefficient and electrical resistivity were measured using the standard 4-probe method (ULVAC ZEM-3) in a He atmosphere. The thermal conductivity was calculated from the measured thermal diffusivity $D$, specific heat $C_{\mathrm{p}}$, and density $d$ according to the relationship $\kappa=D C_{\mathrm{p}} d$. Thermal diffusivity and specific heat of the samples were measured by a laser flash method (Netzsch LFA 427) and differential scanning calorimetry (Shimadzu DSC-50), respectively. All the measurements were performed at a temperature range from room temperature to $800 \mathrm{~K}$.

\section{Results and discussion}

Fig. 1(a) represents the Co-Sb binary phase diagram from Ref.[26]. Due to the presence of a $\mathrm{Co}-\mathrm{Sb}$ peritectic reaction at a temperature of about $876{ }^{\circ} \mathrm{C}$, the $\mathrm{CoSb}_{3}$ 
skutterudite phase could not be directly formed after quenching. This was confirmed by investigating the XRD pattern of the quenched ingot which experienced a $300 \mathrm{~s}$ induction-melting at $1353 \mathrm{~K}$ (see Fig. 1(b)). The ingot consisted of a mixture of $\mathrm{CoSb}, \mathrm{CoSb}_{2}, \mathrm{Sb}$ and $\mathrm{YbSb}_{2}$. No $\mathrm{X}$-ray diffraction peaks belonging to the Skutterudite phase were detected. SEM and EDS analyses shown in Fig. 1(c) further proved the coexistence of $\mathrm{CoSb}, \mathrm{CoSb}_{2}$, and $\mathrm{Sb}$ in the quenched ingot. Presence of these phases formed typical dendrite networks, in which CoSb primary phases encircled with $\mathrm{CoSb}_{2}$ peritectic phases were unevenly distributed in the $\mathrm{Sb}$ matrix. Under higher magnification (see Fig. 1(d)), some bar-shape areas with brighter contrast were also observed in the Sb matrix, which were identified as $\mathrm{YbSb}_{2}$ by EDS. Such microstructure features are identical to that observed in the ingots prepared using a traditional long-term $(48 \mathrm{~h})$ melting process reported in Ref.[27]. However, the melting duration in this study is greatly reduced to as short as $300 \mathrm{~s}$, which is meaningful for future industrial-level mass production.

For the traditional melting-quenching/annealing method, the filled Skutterudite phase could be formed during the annealing process. Long annealing periods of about one week is required to realize the complete reaction among $\mathrm{CoSb}, \mathrm{CoSb}_{2}, \mathrm{Sb}$ and $\mathrm{YbSb}_{2}$ before finally forming the filled Skutterudite phase. This long-term annealing process is quite time-consuming and it greatly limits the fast and massive production of filled Skutterudites. Interestingly, in this study, after grinding the quenched ingot into powder, we found that the mixtures of $\mathrm{CoSb}, \mathrm{CoSb}_{2}, \mathrm{Sb}$, and $\mathrm{YbSb}_{2}$ can be converted into filled Skutterudite phase in a very short time via the SPS process. As shown in Fig. 2, after sintering the powder for just $5 \mathrm{~min}$ at $863 \mathrm{~K}$, most XRD peaks observed in Fig. 1(b) disappear and only three tiny peaks analogous to the $\mathrm{CoSb}_{2}$ and $\mathrm{CoSb}$ phases are remained. Obviously, filled Skutterudite has already become the main phase in the SPSed product. Through enhancing the sintering temperature (or prolonging sintering duration), the X-ray peaks gradually shift to the low angle (see Fig. 2), suggesting that the reaction at a higher temperature (or with longer duration) is more complete and thus more $\mathrm{Yb}$ enters into the voids of Skutterudites to expand the Skutterudite lattice.

The more complete reaction at a higher sintering temperature (or with longer sintering duration) can be further confirmed by the SEM and EDS analyses carried out on the SPSed bulk samples. As shown in Fig. 3, there are lots of secondary phases with different contrasts inside the filled Skutterudite matrix. EDS analyses confirmed that the dark gray areas are $\mathrm{CoSb}$ phases encircled with $\mathrm{CoSb}_{2}$ phases, while the bright areas are $\mathrm{YbSb}_{2}$ and $\mathrm{Sb}$ phases. Obviously, with increasing the sintering temperature or sintering duration, the amount of the secondary phases gradually decreased. For the 943 K-15 min sample, the


Fig. 1 (a) Co-Sb binary phase diagram from Ref. [26], (b) XRD patterns of the quenched sample, and (c, d) back scattering electron images of the quenched sample under different magnification 

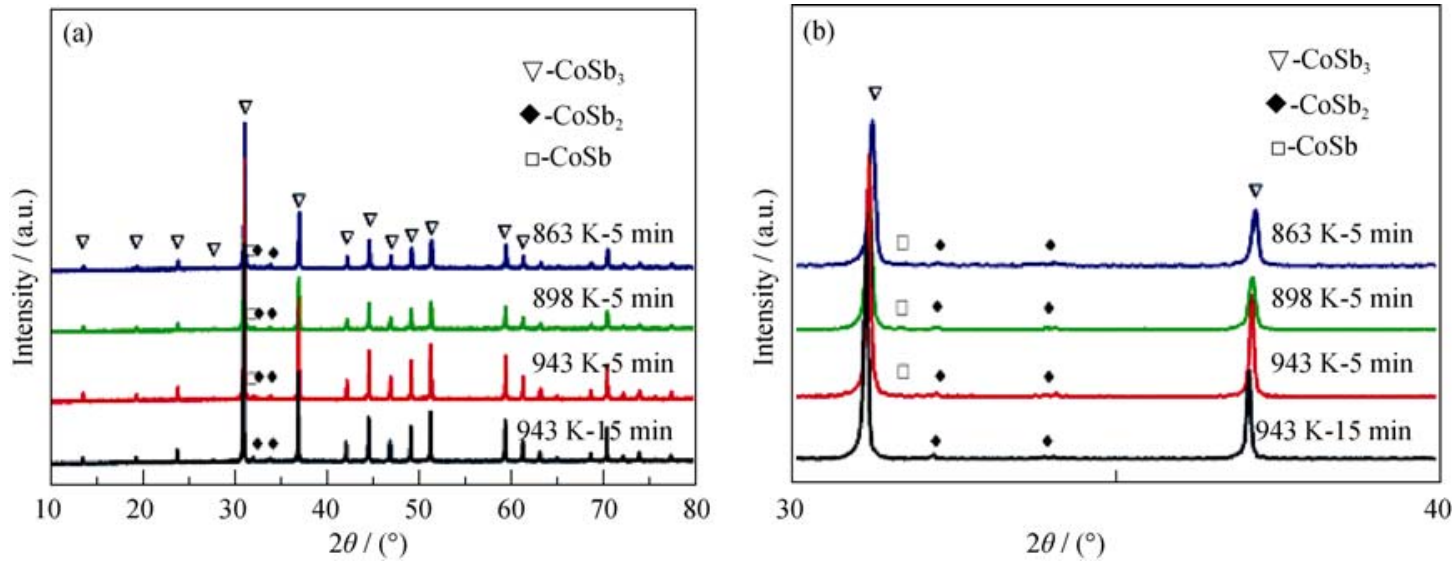

Fig. 2 XRD patterns for the melting-quenching/SPSed samples

$\mathrm{CoSb}$ and $\mathrm{CoSb}_{2}$ phases almost disappeared. Image tools 3.0 software was employed to analyze the amount of impurity phases in the filled skutterudite matrix. It is found that the total amount of the impurity phases decreased from $18.79 \%$ to $8.04 \%$ as the sintering temperature increased from $863 \mathrm{~K}$ to $943 \mathrm{~K}$, and further decreased to $4.94 \%$ as the sintering duration was prolonged to $15 \mathrm{~min}$ at $943 \mathrm{~K}$. Correspondingly, as shown in Fig. 4, the $\mathrm{Yb}$ filling fraction, which is identified by EDS, was also monotonously enhanced and became more homogeneous the sintering temperature and with the sintering duration prolonging increasing. The $943 \mathrm{~K}-15 \mathrm{~min}$ sample has a maximum $\mathrm{Yb}$ filling fraction of 0.19 , which is already comparable with the optimal $\mathrm{Yb}$ filling fraction in $\mathrm{Yb}_{x} \mathrm{Co}_{4} \mathrm{Sb}_{12}$ system reported before ${ }^{[28]}$. This provides another piece of evidence that the reaction is more complete at higher sintering temperature and longer sintering duration.

In order to further understand the fast reaction process during the SPS, the cross-sectional morphology of the melting-quenching/SPSed samples, named as $863 \mathrm{~K}-5 \mathrm{~min}$ and $943 \mathrm{~K}-5 \mathrm{~min}$, were characterized by SEM. These results are presented in Fig. 5(a) and 5(b), respectively. The
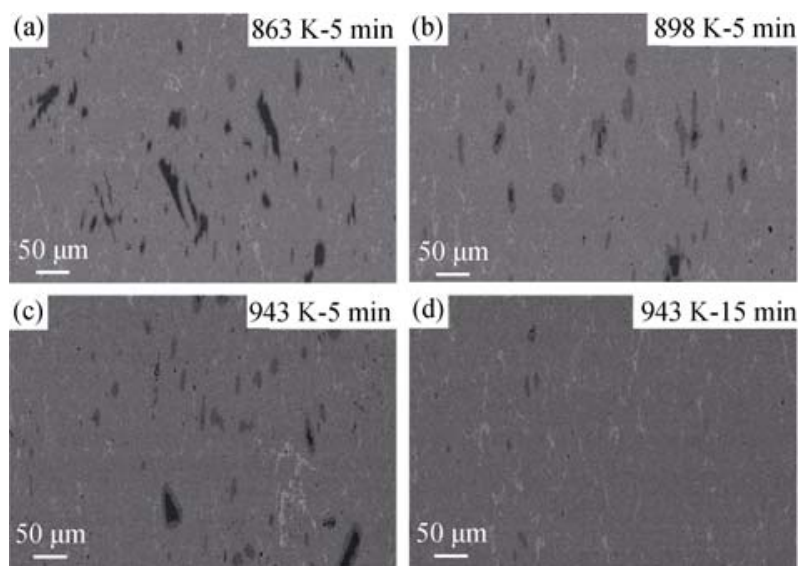

Fig. 3 Back scattering electron images of the melting-quenching/ SPSed samples

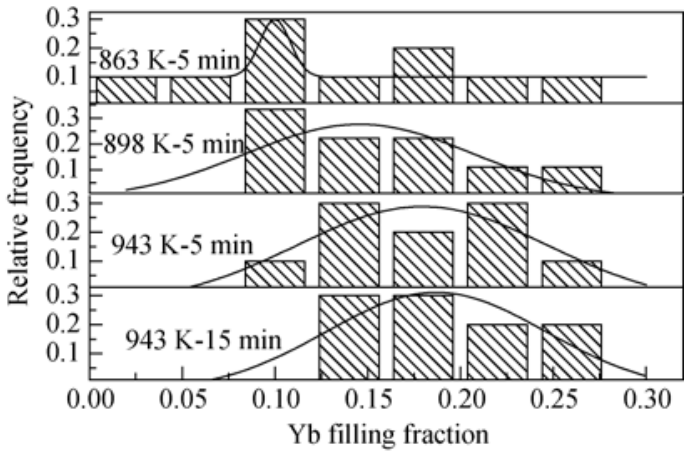

Fig. $4 \mathrm{Yb}$ filling fractions in the melting-quenching/SPSed samples

cross-sectional morphology of the sample TM prepared by the traditional melting-quenching/annealing/SPS method is also presented in Fig. 5(c) for comparison. Obviously, the grain sizes in the melting-quenching/SPSed samples are much smaller than those in the TM sample, which experienced one week annealing at $1073 \mathrm{~K}$. This can be understood as the sintering duration of these melting- quenching/SPSed samples is only $5 \mathrm{~min}$ and therefore the growth of the grains is greatly suppressed. Interestingly, we found many whisker-like crystals throughout the $863 \mathrm{~K}-5$ min sample, which is different from those observed in the $943 \mathrm{~K}-5 \mathrm{~min}$ sample and TM sample. The length of these whisker-like crystals is around $1-10 \mu \mathrm{m}$ and the width is around $0.2-1 \mu \mathrm{m}$. The formation of these whisker- like crystals might be caused by the low sintering temperature and short sintering duration, which limit the sufficient growth of the filled Skutterudite grains ${ }^{[29]}$. Under higher SEM magnification (Fig. 5(d)), it was found that some whisker-like crystals are divergent from one small center area consisting of lots of closely packed nano-sized grains. EDS analyses confirmed that these whisker-like crystals are filled Skutterudite phases while the nano-sized grains in the inner areas are $\mathrm{CoSb}_{2}$ phases (Fig. 5(e) and 5(f)). Such distribution is consistent with the SEM image shown in Fig. 5(a), in which the CoSb and $\mathrm{CoSb}_{2}$ phases are surrounded by the filled skutterudite 
phase, suggesting that the reaction was not complete in the $863 \mathrm{~K}-5$ min sample.

Fig. 6 shows a sketch of the possible reaction mechanism in the annealing process for the traditional melting-quenching/annealing method. In the quenched ingot, the $\mathrm{CoSb}$ primary phases encircled with $\mathrm{CoSb}_{2}$ peritectic phases were unevenly distributed in the $\mathrm{Sb}+\mathrm{YbSb}_{2}$ matrix, as shown in Fig. 1(c) and 1(d). Such microstructure is inherited at the beginning of annealing process. Then, through annealing at elevated temperatures, the inner $\mathrm{CoSb}$ primary phases would be gradually converted to the $\mathrm{CoSb}_{2}$ phases and meanwhile the initial $\mathrm{CoSb}_{2}$ phase would transfer to $\mathrm{CoSb}_{3}$ phase due to their reaction with $\mathrm{Sb}$ in the annealing process. In this case, the microstructure would evolve into the middle-state, as shown in Fig. 6(a). Further prolonging the annealing period, most of the $\mathrm{CoSb} / \mathrm{CoSb}_{2}$ phases completely reacted with the remaining $\mathrm{Sb}+\mathrm{YbSb}_{2}$ phases, forming the final single $\mathrm{Yb}$-filled Skutterudite phase. However, a minor amount of the $\mathrm{CoSb} / \mathrm{CoSb}_{2}$ phases might be still reserved at the place where the $\mathrm{CoSb} / \mathrm{CoSb}_{2}$ peritectic segregation is very severe. Besides longer annealing duration, enough Sb-source nearby is also an essential factor to completely eliminate these $\mathrm{CoSb} / \mathrm{CoSb}_{2}$ phases. Our previous investigation proved that the Skutterudite formation process is dominated by the Sb-diffusion process ${ }^{[27]}$. Clearly, the results shown in Fig. 5 suggest that the present melting-quenching/ SPS process can also achieve the middle-state and final-state mentioned above and thus the reaction mechanism should share similarities with that in the traditional annealing process. However, it should not be the only one reaction mechanism because of the much faster reaction rate in the present SPS process $(5 \mathrm{~min})$ than that in the traditional annealing process (one week). Prior to the SPS process, the quenched ingot is ground into fine powder. In this case, the dendrite networks (Fig. 1(c)), or even part of the $\mathrm{Sb} / \mathrm{CoSb} / \mathrm{CoSb}_{2}$ peritectic structure in the quenched ingot (Fig. 1(d)), would be destroyed. Part of Sb phases can then be directly in contact with the $\mathrm{CoSb}$ primary phases without experiencing the long diffusion process in the $\mathrm{CoSb}_{2}$ peritectic phase as shown in Fig. 6(b). This would definitely lead to a much faster reaction rate, as mentioned above. Meanwhile, the grinding process can also greatly increase the contacting surfaces among those of $\mathrm{CoSb}, \mathrm{CoSb}_{2}, \mathrm{Sb}$ and $\mathrm{YbSb}_{2}$ phases and shrink the diffusion path for each element before forming the final filled skutterudite phase. These factors, combining the activated reaction induced by the current heating among contacting particles during the SPS, can explain the fast reaction rate observed in this present study.

Fig. 7 displays the temperature dependences of electrical conductivity, Seebeck coefficient, thermal conductivity, lattice thermal conductivity, power factor, and $Z T$ values for the four samples prepared using the melting-quenching/ SPS process. The data for the TM sample prepared by the traditional melting-quenching/annealing/SPS process are also included for comparison. For filled skutterudites, the filling fraction of filler atoms in the voids dominated the electrical and thermal transport. Higher filling fraction would lead to a larger electrical conductivity, smaller Seebeck coefficient, and lower lattice thermal conductivity. These effects are reflected by the data shown in Fig. 7. As the sintering temperature increased from $863 \mathrm{~K}$ to $943 \mathrm{~K}$, the $\mathrm{Yb}$ filling fraction gradually increased (Fig. 4) and
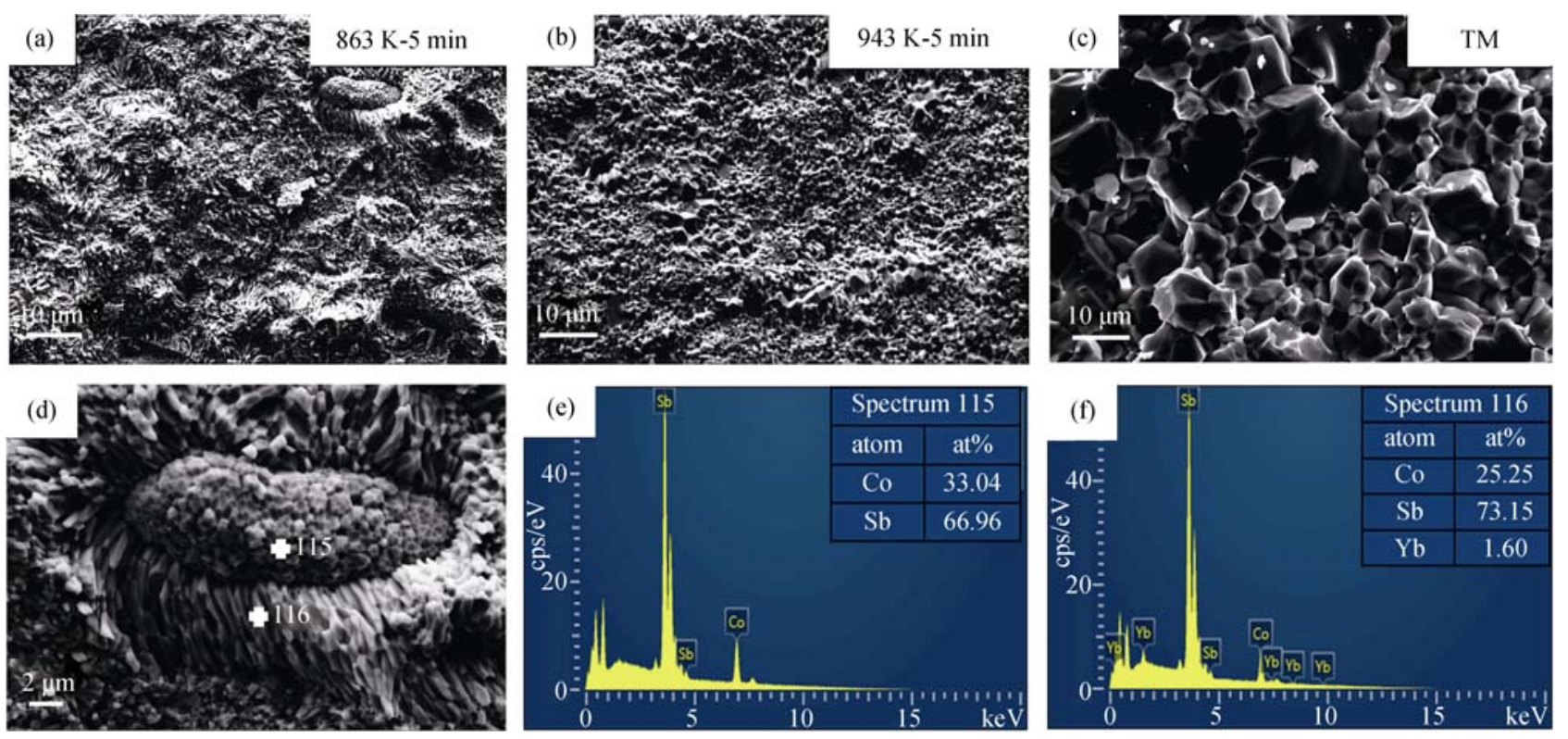

Fig. 5 Cross-section morphologies for the samples (a) 863 K-5 min, (b) 943 K-5 min and (c) TM, respectively, and (d) magnified image of (a), and (e, f) the EDS analyses on the two points (spectrum 115 and 116) shown in (d) 


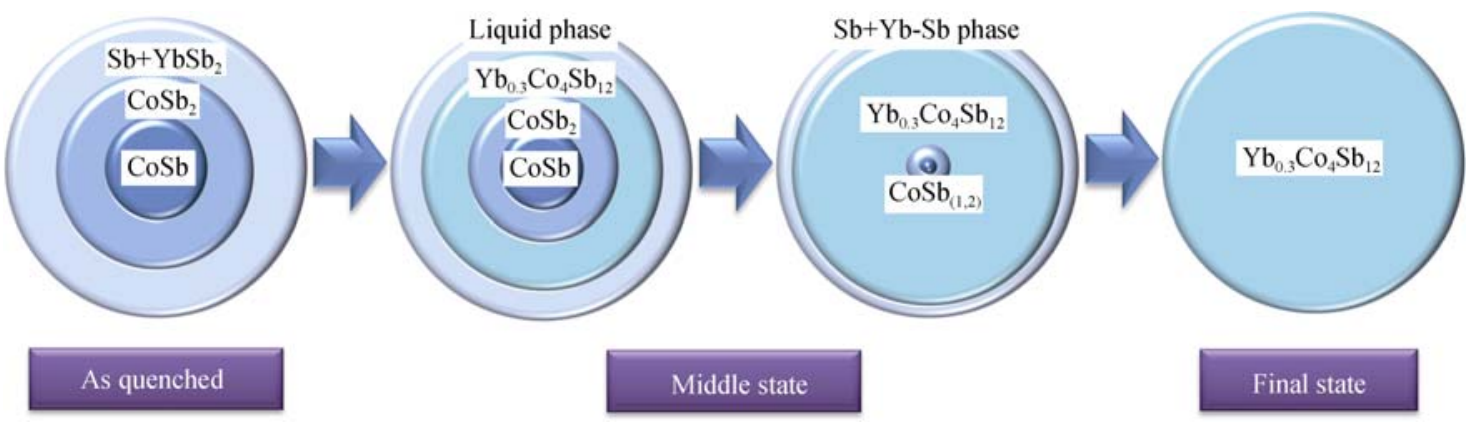

Fig. 6 Sketch of the reaction mechanism in the annealing process for the traditional melting-quenching/annealing method
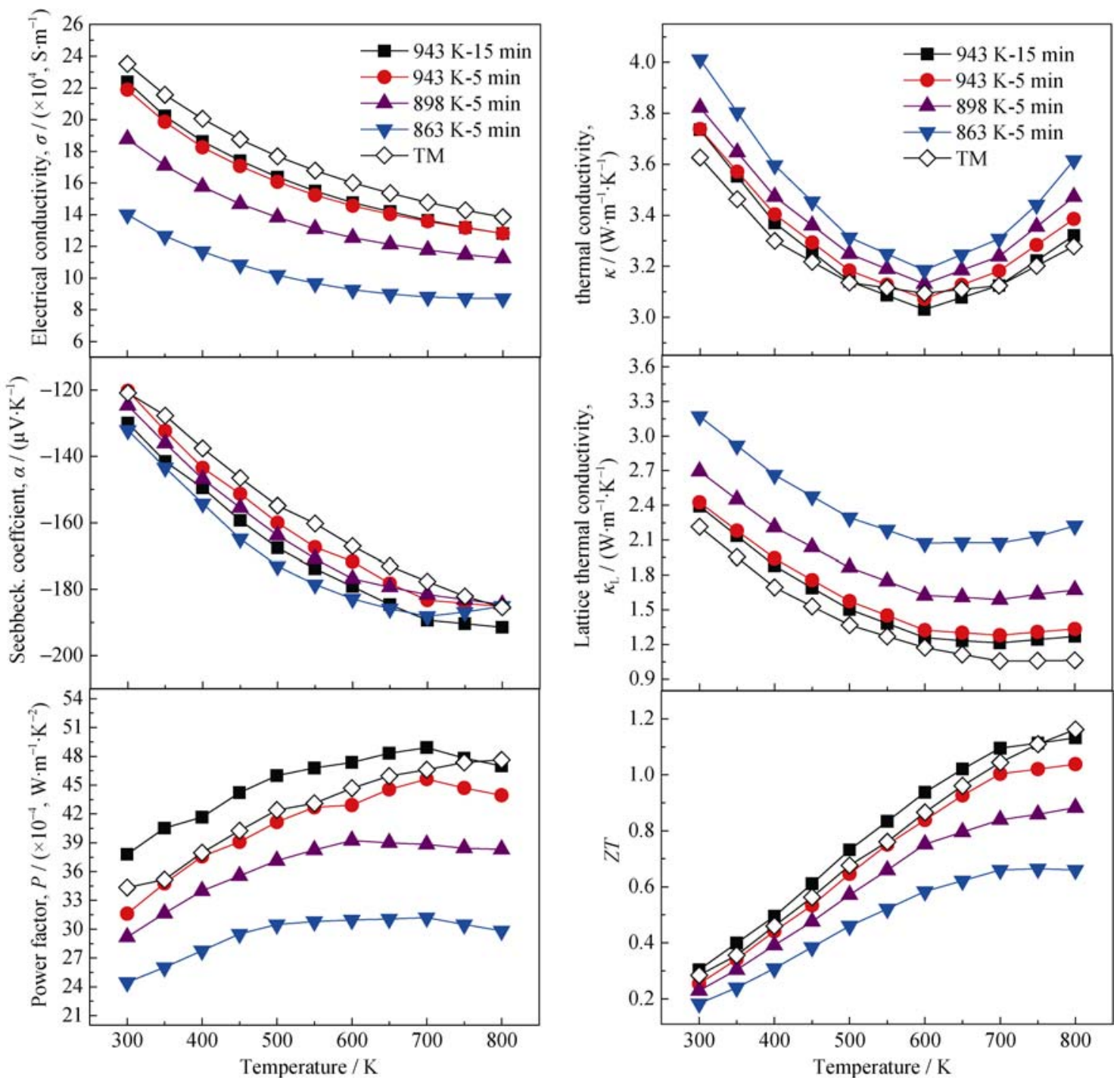

Fig. 7 Temperature dependences of TE properties of the samples prepared by the melting-quenching/SPS method The data for the TM sample are also included for comparison

consequently the electrical conductivity also monotonously increased, accompanied with a decrease in the Seebeck coefficient and lattice thermal conductivity. The power factor for the $943 \mathrm{~K}-5$ min sample was almost the same with that of the TM sample and those previously reported $^{[28]}$. The maximum $Z T$ for the $943 \mathrm{~K}-5$ min sample was around 1.0 at $800 \mathrm{~K}$. Prolonging the sintering duration from $5 \mathrm{~min}$ to $15 \mathrm{~min}$ at $943 \mathrm{~K}$, the $Z T$ can be further en- hanced to 1.1, which might be ascribed to the less secondary phases within the 943 K-15 min sample. Clearly, this $Z T$ value is comparable with the results of TM sample previously reported ${ }^{[28]}$, while the synthesis period was greatly decreased due to the shrinkage of the melting process and the omitted time-consuming long-term annealing process. Therefore, this melting-quenching/SPS process can be a convenient, fast, and massive method for 
the future industrial-level mass production of n-type filled Skutterudites.

\section{Conclusions}

In this study, the melting-quenching/SPS method has been used to prepare n-type filled skutterudites. After short-term (300 s) induction melting, the quenched $\mathrm{Yb}_{0.3} \mathrm{Co}_{4} \mathrm{Sb}_{12}$ ingot was ground into fine powder and then sintered directly by SPS. The filled skutterudite phase can be rapidly formed during SPS process. This filling was a cause of the destruction of the dendrite networks and part of the $\mathrm{Sb} / \mathrm{CoSb} / \mathrm{CoSb}_{2}$ peritectic structure in the grinding process. The EDS analyses confirmed that after $15 \mathrm{~min}$ sintering at $943 \mathrm{~K}$, the $\mathrm{Yb}$ filling fraction reached around 0.19 , which is close to the optimal $\mathrm{Yb}$ filling fraction in $\mathrm{Yb}_{x} \mathrm{Co}_{4} \mathrm{Sb}_{12}$ system previously reported. Correspondingly, the $943 \mathrm{~K}-15 \mathrm{~min}$ sample displayed high $Z T$ value being comparable with the sample prepared by a conventional melting-quenching/annealing/SPS process. When compared with the time-consuming melting-quenching/annealing/SPS fabrication process, the present method is simpler, faster and cheaper as a practical technique for the future industriallevel mass production of n-type filled skutterudites.

\section{References:}

[1] TRITT T M. Holey and unholey semiconductors. Science, 1999, 283(5403): 804-805.

[2] SNYDER GERALD JEFFREY, ERIC S TOBERER. Complex thermoelectric materials. Nature Materials, 2008, 7: 105-114.

[3] LIU HUI-LI, SHI XUN, XU FANG-FANG, et al. Copper ion liquid-like thermoelectric. Nature Materials, 2012, 11(5): 422-425.

[4] JUNG DO-YOUNG, KUROSAKI KEN, KIM CHANG-EUN, et al. Thermal expansion and melting temperature of the half-Heusler compounds: MNiSn (M=Ti, Zr, Hf). Journal of Alloys and Compounds, 2010, 489(2): 328-331.

[5] HE YING, LU PING, SHI XUN, et al. Ultrahigh thermoelectric performance in mosaic crystals. Advanced Materials, 2015, 27(24): 3639-3644.

[6] HE YING, DAY TRISTAN, ZHANG TIAN-SONG, et al. High thermoelectric performance in non-toxic earth-abundant copper sulfide. Advanced Materials, 2014, 26(23): 3974-3978.

[7] SHI XUN, YANG JIONG, SALVADOR JAMES R, et al. Multiple-filled skutterudites: high thermoelectric figure of merit through separately optimizing electrical and thermal transports. Journal of the American Chemical Society, 2011, 133(20): 7837-7846.

[8] ROGL G, GRYTSIV A, ROGL P, et al. n-type skutterudites $(\mathrm{R}, \mathrm{Ba}, \mathrm{Yb})_{(y)} \mathrm{Co}_{4} \mathrm{Sb}_{12}(\mathrm{R}=\mathrm{Sr}, \mathrm{La}, \mathrm{Mm}, \mathrm{DD}, \mathrm{SrMm}, \mathrm{SrDD})$ approaching
ZT approximate to 2.0. Acta Materialia, 2014, 63: 30-43.

[9] LIU WEI-SHU, JIE QING, KIM HEE SEOK, et al. Current progress and future challenges in thermoelectric power generation: from materials to devices. Acta Materialia, 2015, 87: 357-376.

[10] YANG JI-HUI, STABLER FRANCIS R. Automotive applications of thermoelectric materials. Journal of Electronic Materials, 2009, 38(7): $1245-1251$.

[11] ZHANG QI-HAO, HUANG XIANG-YANG, BAI SHENGQIANG, et al. Thermoelectric devices for power generation: recent progress and future challenges. Advanced Engineering Materials, 2016, 18(2): 194-213.

[12] TANG YUN-SHAN, BAI SHENG-QIANG, REN DU-DI, et al. Interface structure and electrical property of $\mathrm{Yb}_{0.3} \mathrm{Co}_{4} \mathrm{Sb}_{12} \mathrm{Mo}-\mathrm{Cu}$ element prepared by welding using $\mathrm{Ag}-\mathrm{Cu}-\mathrm{Zn}$ solder. Journal of Inorganic Materials, 2015, 30(3): 256.

[13] RECKNAGEL C, REINFRIED N, HOHN P, et al. Application of spark plasma sintering to the fabrication of binary and ternary skutterudites. Science and Technology of Advanced Materials, 2007, 8(5): 357-363.

[14] SHI X, KONG H, LI C P, et al. Low thermal conductivity and high thermoelectric figure of merit in n-type $\mathrm{Ba}_{x} \mathrm{Yb}_{y} \mathrm{Co}_{4} \mathrm{Sb}_{12}$ double-filled skutterudites. Applied Physics Letters, 2008, 92(18): 182101.

[15] SU XIAN-LI, LI HAN, WANG GUO-YU, et al. Structure and transport properties of double-doped $\mathrm{CoSb}_{2.75} \mathrm{Ge}_{0.25-x} \mathrm{Te}_{x}(x=$ 0.125-0.20) with in situ nanostructure. Chemistry of Materials, 2011, 23(11): 2948-2955.

[16] WU TING, BAI SHENG-QIANG, SHI XUN, et al. Enhanced thermoelectric properties of $\mathrm{Ba}_{x} \mathrm{Eu}_{y} \mathrm{Co}_{4} \mathrm{Sb}_{12}$ with very high filling fraction. Journal of Inorganic Materials, 2013, 28(2): 224-228.

[17] YANG JUN-YOU, CHEN YUE-HUA, ZHU WEN, et al. Effect of La filling on thermoelectric properties of $\mathrm{La}_{x} \mathrm{Co}_{3.6} \mathrm{Ni}_{0.4} \mathrm{Sb}_{12}$-filled skutterudite prepared by MA-HP method. Journal of Solid State Chemistry, 2006, 179(1): 212-216.

[18] LIU WEI-SHU, ZHANG BO-PING, LI JING-FENG, et al. Enhanced thermoelectric properties in $\mathrm{CoSb}_{3-x} \mathrm{Te}_{x}$ alloys prepared by mechanical alloying and spark plasma sintering. Journal of Applied Physics, 2007, 102(10): 103717.

[19] BISWAS KRISHNENDU, MUIR SEAN, SUBRAMANIAN M A. Rapid microwave synthesis of indium filled skutterudites: an energy efficient route to high performance thermoelectric materials. Materials Research Bulletin, 2011, 46(12): 2288-2290.

[20] ZHANG JIAN-JUN, XU BO, WANG LI-MIN, et al. High-pressure synthesis of phonon-glass electron-crystal featured thermoelectric $\mathrm{Li}_{x} \mathrm{Co}_{4} \mathrm{Sb}_{12}$. Acta Materialia, 2012, 60(3): 1246-1251.

[21] LIANG TAO, SU XIAN-LI, YAN YONG-GAo, et al. Ultra-fast 
synthesis and thermoelectric properties of Te doped skutterudites. Journal of Materials Chemistry A, 2014, 2(42): 17914-17918.

[22] LI HAN, TANG XIN-FENG, ZHANG QING-JIE, et al. Rapid preparation method of bulk nanostructured $\mathrm{Yb}_{0.3} \mathrm{Co}_{4} \mathrm{Sb}_{12+y}$ compounds and their improved thermoelectric performance. Applied Physics Letters, 2008, 93(25): 252109.

[23] LI HAN, TANG XIN-FENG, ZHANG QING-JIe, et al. High performance $\mathrm{In}_{x} \mathrm{Ce}_{y} \mathrm{Co}_{4} \mathrm{Sb}_{12}$ thermoelectric materials with in situ forming nanostructured InSb phase. Applied Physics Letters, 2009, 94(10): 102114.

[24] YU JIAN, ZHAO WEN-YU, ZHOU HONG-YU, et al. Rapid preparation and thermoelectric properties of $\mathrm{Ba}$ and $\mathrm{In}$ double-filled p-type skutterudite bulk materials. Scripta Materialia, 2013, 68(8): 643-646.

[25] ZHAO X Y, SHI X, CHEN L D, et al. Synthesis and thermoelectric properties of Sr-filled skutterudite $\mathrm{Sr}_{y} \mathrm{Co}_{4} \mathrm{Sb}_{12}$. Journal of Applied Physics, 2006, 99(5): 053711 .

[26] HANNINGER G, IPSER H, TERZIEFF P, et al. The Co-Sb phasediagram and some properties of NiAs-type $\mathrm{Co}_{1+/ x} \mathrm{Sb}$. Journal of the Less-Common Metals, 1990, 166(1): 103-114.

[27] YAO ZHENG, LI XIAO-YA, TANG YUN-SHAN, et al. Genomic effects of the quenching process on the microstructure and thermoelectric properties of $\mathrm{Yb}_{0.3} \mathrm{Co}_{4} \mathrm{Sb}_{12}$. Journal of Electronic Materials, 2014, 44(6): 1890-1895.

[28] ZHAO XUE-YIN, SHI XUN, CHEN LI-DONG, et al. Synthesis of $\mathrm{Yb}_{\mathrm{y}} \mathrm{Co}_{4} \mathrm{Sb}_{12} / \mathrm{Yb}_{2} \mathrm{O}_{3}$ composites and their thermoelectric properties. Applied Physics Letters, 2006, 89(9): 092121.

[29] ZHOU H. Preparation and Thermoelectric Properties of Nonequilibrium-structure Filled Skutterudite Based Thermoelectric Materials. Wuhan University of Technology, 2011: 41.

\title{
$\mathrm{n}$ 型填充方钴矿热电材料的快速制备研究
}

\author{
姚 铮 $^{1,2}$, 仇鹏飞 ${ }^{2}$, 李小亚 ${ }^{2}$, 陈立东 ${ }^{2}$ \\ (1. 中国科学院大学, 北京 $100049 ; 2$. 中国科学院 上海硅酸盐研究所, 上海 200050)
}

摘 要: 如何有效控制方钴矿基热电材料的制备成本成为其商业化应用的瓶颈。本课题组采用一种简单并且可放量的 方法来制备 $\mathrm{n}$ 型填充方钴矿热电材料。该法由感应熔融淬、火和放电等离子烧结(SPS)组成, 制备周期(少于 $30 \mathrm{~min}$ ) 远小于传统制备方法: 电阻炉熔融(超过 $24 \mathrm{~h})$, 退火 $(1 \mathrm{w})$ 和 SPS。该法同传统制备工艺相当, 制备的方钴矿块体材料 具有相对均匀的物相成份和组织结构, 以及良好的热电性能, 这得益于将经历感应熔融、淬火冷凝工艺形成的 $\mathrm{Sb} / \mathrm{CoSb} / \mathrm{CoSb}_{2}$ 包晶偏析结构破坏，能同时实现快速反应和致密化。良好的热电性能和较少的生产周期及能耗，使该 法有望发展成为具有潜在应用前景的填充方钴矿热电材料工业化制备工艺。

关 键 词: 填充方钴矿材料; 熔融-淬火/放电等离子烧结; 微观组织结构; 热电性能 中图分类号: TQ174 文献标识码: A 